- The General Dental Council recommends the use of conscious sedation in preference to general anaesthesia whenever possible.

- In a survey of Welsh primary dental care practitioners, over half had referred patients for conscious sedation.

- Only $12 \%$ of those surveyed offered sedation services for patients

\title{
Sedation in Wales: a questionnaire
}

\author{
B. L. Chadwick, ${ }^{1}$ S. Thompson ${ }^{2}$ and E. T. Treasure ${ }^{3}$
}

\begin{abstract}
Aim To identify the current provision of sedation in primary dental care in Wales.

Design Postal questionnaire survey.

Setting Wales 2003.

Subjects and materials Questionnaires were sent to all dentists appearing on the Dentists Register with addresses in Wales $(n=1,374)$.

The questionnaires sought details on personal status, use of and training in conscious sedation techniques.

Results In total 951 (69\%) questionnaires were returned, 720 (90\%) respondents worked in a primary dental care setting. Only 87 (12.1\%) primary care dentists offered some form of sedation.

Conclusions The provision of conscious sedation services in primary dental care in Wales is poor.
\end{abstract}

\section{INTRODUCTION}

Recent guidelines from both Government ${ }^{1}$ and General Dental Council $^{2}$ have stressed the need to avoid general anaesthesia whenever possible and advise the adoption of alternative techniques such as conscious sedation. Within Wales the number of sites offering access to general anaesthetic services was reduced following GDC guidance in December 1998, so few primary care facilities in Wales offer general anaesthetic services. The Poswillo report ${ }^{3}$ recommended inhalation sedation together with local anaesthesia as an alternative to general anaesthesia, particularly for children. Dental anxiety remains a significant barrier to care for many patients ${ }^{4}$ and conscious sedation via oral, intravenous and inhalational routes has been shown to be a safe alternative to general anaesthesia in many cases. ${ }^{5-8}$

Few studies have investigated the availability of sedation services in dental practice in the United Kingdom. Questionnaire surveys of primary care practitioners in the UK have reported the use of sedation techniques to vary between $37-51 \%$ of practices in North England ${ }^{9}$ and $49 \%$ practitioners in a primary care trust in Scotland. ${ }^{10}$ However, there were marked differences in the type of sedation offered in these surveys.

\footnotetext{
${ }^{1 *}$ Professor in Paediatric Dentistry, ${ }^{2}$ Senior Lecturer in Adult Dental Health, ${ }^{3}$ Professor of Dental Public Health, Department of Dental Health \&t Biological Sciences, Dental School, University of Cardiff, Heath Park, Cardiff, CF4 4XY

${ }^{*}$ Correspondence to: Dr Barbara Chadwick

Email:Chadwickbl@cardiff.ac.uk
}

In 2000 a questionnaire was sent to all dentists practicing in Wales by the Department of Postgraduate Dental Education of the University of Wales College of Medicine to determine how many practitioners have had or how many would like to receive training in conscious sedation techniques. Only 69 of 579 returns (12\%) indicated that they provided conscious sedation techniques (personal communication, 2004). In the intervening period approximately 50 dentists have attended basic training courses run by the postgraduate department. The purpose of this study was to identify the current provision of sedation in primary dental care in Wales.

\section{METHOD}

The study was a questionnaire-based survey undertaken in the Principality of Wales during August 2002-April 2003. Questionnaires with a covering letter explaining the purpose of the study were sent to all dentists appearing on the Dentists Register (2002) with addresses in Wales. The initial posting was in August 2002 and a follow up questionnaire was sent in March 2003 to non-responders.

The questionnaire identified:

Practitioner details:

- Gender

- Year of qualification

- Postcode of practice

- Sector of practice

- Generalist or specialist

- Whether sedation was offered

Those not offering sedation were asked:

- Availability of sedation services locally

- Number of children and adults referred

- Training of dentists providing sedation

- Availability of GA services locally

- Number of children and adults referred

Those offering a sedation service were also asked:

- Types of patient treated (adults/children)

- Routes of administration

- Sedative agents used

- Training received for sedation

- Details of the team undertaking sedation

- Funding arrangements (GDS practitioners only)

Space was also left for specific comments. 
Table 1 Year of qualification for all responding dentists and primary care dentists offering sedation

\begin{tabular}{|l|l|l|l|l|l|l|l}
\hline Year qualified $n(\%)$ & Pre '62 & '63-'72 & '73-'82 & '83-'92 & '93-'02 & No reply & Total \\
\hline All dentists & $9(1)$ & $143(18)$ & $276(34.5)$ & $215(27)$ & $151(19)$ & $3(0.5)$ & $797(100)$ \\
\hline Offer sedation & $1(1)$ & $12(14)$ & $29(33)$ & $31(36)$ & $14(16)$ & $0(0)$ & $87(100)$ \\
\hline
\end{tabular}

\section{Table 2 Type of dental practice}

\begin{tabular}{|c|c|c|c|c|c|}
\hline Location & GDS & CDS & HDS & PDS & Other \\
\hline$n(\%)$ & $646(81)$ & $91(11.5)$ & $68(8.5)$ & $11(1.5)$ & $32(4)$ \\
\hline
\end{tabular}

Table 3 Type of sedation offered by primary care dentists in children and adults

\begin{tabular}{l|c|c}
\hline $\begin{array}{l}\text { Type of sedation offered } \\
\text { in the practice }\end{array}$ & For children & For adults \\
\hline Inhalation sedation (IS) & 29 & 19 \\
\hline Intravenous (IV) & 6 & 16 \\
\hline Oral & 9 & 20 \\
\hline IS and IV & 2 & 3 \\
\hline IS and oral & 5 & 5 \\
\hline IV and oral & 5 & 10 \\
\hline IS, IV and oral & 1 & 9 \\
\hline Do not offer & 27 & 5 \\
\hline Total & 87 & 87 \\
\hline
\end{tabular}

\section{RESULTS}

A total of 1,374 questionnaires were sent to dentists on the GDC register with addresses in Wales. Of these 951 (69.21\%) were returned, of which 154 were not useable (dentist retired, deceased, worked outside of Wales). Thus 797 valid returns were received, although not all respondents filled in all sections.

541 respondents were male, 253 were female and three did not give details of gender. The year of qualification for the whole sample and for primary care dentists offering sedation is detailed in Table 1, again three dentists failed to reply.

When asked about the style of practice, 673 (84.5\%) considered themselves to be generalists, $96(12 \%)$ reported that they were in specialist practice and 28 (3.5\%) did not respond. Table 2 details the type of practice, it should be noted that multiple responses were possible. In total 720 respondents (90.3\%) indicated that they were in either the general dental services or community dental services for some of their working week. As this survey was interested in the provision of sedation in primary dental care, the remainder of the results only considers responses from these individuals, with the exception of free comments which are reported for all respondents.

In total $87(12.1 \%)$ primary care dentists offered some form of sedation; almost two thirds of them $(n=57,65.5 \%)$ were in the general dental services (GDS), 24 (27.6\%) the community dental services (CDS) and six (6.9\%) in both GDS and CDS. For this latter group it is not possible to determine the service in which they offer sedation. Of those offering sedation, 82 (94.3\%) treated adults and $60(70 \%)$ treated children (57 treated both).

Table 3 details the type of sedation used in both adults and children by those dentists who offered it. When considering children, inhalation sedation (IS) was offered by the greatest number of dentists ( $n=37,42.5 \%)$, followed by oral sedation $(n=20,23 \%)$, with intravenous sedation (IV) being the sedation format used least (n $=17,19.5 \%)$. For adults just over half $(\mathrm{n}=44,50.6 \%)$ of dentists

\begin{tabular}{|c|c|}
\hline Type of training & $\begin{array}{l}\text { Dentists offering sedation } \\
\mathrm{n} \quad \%\end{array}$ \\
\hline Undergraduate & 20 \\
\hline Postraduate & 44 \\
\hline Undergraduate \& Postgraduate & 24 \\
\hline None & 9 \\
\hline Not answered & 3 \\
\hline Total & 100 \\
\hline
\end{tabular}

offered oral sedation, with 38 (43.7\%) and 36 (41.4\%) offering IV and IS respectively.

Table 4 details the reported training of the 87 primary care practitioners offering sedation. Some training (at undergraduate, postgraduate or both) was reported by 76 (87\%) of them, with 59 (68\%) having received some form of postgraduate training. Practitioners not offering sedation were not asked to complete this section.

Table 5 details the staff present when sedation was administered based on the level of training reported by those dentists offering sedation; it should be noted that multiple responses were possible. As can be seen, only two of the dentists offering sedation did not complete this section. Dental nurses (DN) are the group most frequently present during the administration of sedation and were used by all dentists who answered the question; qualified DNs were used by $66 \%$ of respondents. Overall, sedation certificated DNs were used by $23 \%$ of dentists offering sedation; their usage by dentists who had undergone postgraduate training of some sort was slightly higher (29\%).

Of the 797 dentists who responded to the survey, 422 (52.9\%) had referred patients for sedation, $213(26.7 \%)$ had never referred patients for sedation and 162 (20.3\%) did not respond. A total of 418 (52.4\%) had referred for general anaesthesia, 208 (26.1\%) had not referred for general anaesthesia and 178 (22.3\%) did not reply. A total of 513 respondents answered the question on how long it would take a patient they referred for sedation to travel to the referral centre. Table 6 details their responses. Just over half (51\%) estimated a 30 minute journey to the nearest sedation centre.

The free comments section was used by a number of dentists, with several themes being repeated. In total 74 respondents said that sedation services were inadequate or the waiting times were too long; 45 replies indicated that finance was an issue, either in terms of it not being economic to offer it under NHS contract or the need for more funds to support local centres. Thirty-three replies were positive about local specialist centres (hospital, community and practice based). Nine respondents were planning to offer sedation or were undergoing training, and six felt there was a need for more courses or a diploma in sedation.

The majority of respondents gave the postcode of their practices on the questionnaire. By using this information from respondents that currently offer sedation, the availability of primary care practitioners offering sedation can be deduced. Figure 1 shows the dentist:population ratio in areas of Wales, derived from Welsh 


\begin{tabular}{|c|c|c|c|c|c|c|c|}
\hline \multirow[b]{2}{*}{ Type of training } & \multicolumn{6}{|c|}{ Who is present when sedation is administered? } & \multirow[b]{2}{*}{$\begin{array}{l}\text { Dentists offering } \\
\text { sedation who replied }\end{array}$} \\
\hline & Another dentist & Anaesthetist & $\begin{array}{l}\text { Dental nurse sedation } \\
\text { certificated }\end{array}$ & $\begin{array}{l}\text { Dental nurse } \\
\text { qualified }\end{array}$ & $\begin{array}{l}\text { Dental nurse } \\
\text { unqualified }\end{array}$ & Not answered & \\
\hline Undergraduate & 1 & 1 & - & 14 & 1 & - & 17 \\
\hline Postraduate & 7 & 5 & 12 & 27 & 6 & - & 38 \\
\hline $\begin{array}{l}\text { Undergraduate \& } \\
\text { Postgraduate }\end{array}$ & 3 & 2 & 5 & 12 & 3 & - & 21 \\
\hline None & - & 1 & 2 & 4 & 2 & - & 8 \\
\hline Not answered & - & - & 1 & - & - & 2 & 3 \\
\hline Total & 11 & 9 & 20 & 57 & 12 & 2 & 87 \\
\hline
\end{tabular}

\begin{tabular}{|l|lc|}
\hline \multicolumn{3}{|l|}{ Table 6 Dentists' estimate of time for travel to sedation centre/practice } \\
\hline Time & Number & $\%$ \\
\hline Less than 30 minutes & 123 & 24 \\
\hline 30 minutes & 262 & 51 \\
\hline $31-60$ minutes & 103 & 20 \\
\hline More than 60 minutes & 25 & 5 \\
\hline Total & 513 & 100
\end{tabular}

Assembly Government data; the darker the shading the better the ratio. For each of the 22 Local Health Boards, the actual number of dentists and population is given; in parentheses after this the number of primary care sedationists responding to this survey in the area is given. It does not indicate the number of practices offering sedation, since several practitioners may work out of the same centre. The data show wide variation in the availability of primary dental care sedationists; not all areas with a high dentist to population ratio have access to a primary care sedationist, while some areas with generally poor dentist to population ratios have relatively high numbers of sedationists.

\section{DISCUSSION}

The response rate for this questionnaire was almost 70\% and can therefore be expected to give a reasonable representation of current conscious sedation practices in Wales. Only 12\% of responding primary care practitioners were offering some form conscious sedation; this is much lower than previous UK studies in Grampian ${ }^{10}$ and Northern England, ${ }^{9}$ where $49 \%$ and $42 \%$ of primary care practitioners were offering some form of service. Interestingly, the percentage of dentists offering sedation in Wales does not appear to have changed since the unpublished Department of Postgraduate Dental Education survey of 2000, a disappointing finding given that the department has run two basic conscious sedation courses a year, held alternately in South and North Wales, since May 2001.

It is interesting to note that more dentists offer sedation to adults $(n=82)$ than offer the service for children $(n=60)$. Amongst those treating adults, oral sedation was used most frequently and was used exclusively by almost a quarter of those treating adults. However, all three techniques were widely used (range 41 to $51 \%$ of practitioners). While some practitioners used only IS, practitioners who reported usage of intravenous sedation always used at least one other form of sedation in their practice as well. IS was used most frequently in children, and exclusively by almost half of those treating children with sedation. Current guidance from the GDC $^{2}$ and Standing Dental Advisory Committee ${ }^{12}$ suggests that IV sedation is rarely justified in children, but almost a fifth of respondents in this study reported the use of IV sedation in this group (defined in this study as under 16 years). However, as it is

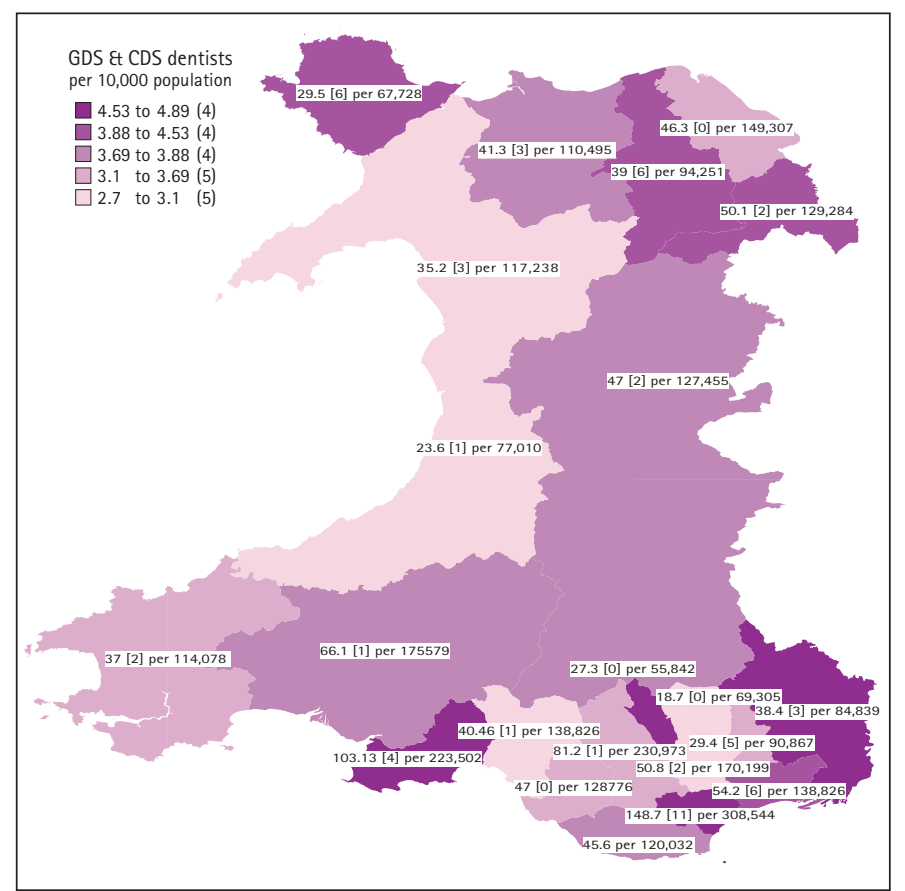

Fig. 1 Primary care dentist: population ratio for 22 Local Health Board Area (LHB) in Wales. For each LHB the number of dentists and population are given the number of practitioners offering sedation appears in parenthesis. (Based on Welsh Assembly Government data ${ }^{11}$ )

not possible to determine exactly how old the children receiving sedation were in the present research, it is difficult to identify how important this statistic is.

The pattern of usage reported in Wales appears to be different to previous UK studies of sedation in primary dental care. ${ }^{9,10}$ However, neither of the previous studies reported adults and children separately; the figures reported therefore probably relate to sedation in children and adults. Foley ${ }^{10}$ found that intravenous sedation was most commonly used by 163 dentists in the Grampian region (82\%) followed by oral (32\%) and IS (19\%). The same order of usage was reported in South Durham ${ }^{9}$ where of 89 dentists, $41 \%$, $31 \%$ and $8 \%$ respectively used IV, oral and IS. However, in this group of practitioners IS was used only in patients under 18 years of age. The same authors also reported figures for 175 dentists in Bradford. Here oral sedation was most common (23\%), IV least used (7\%) and the 16\% who used IS used it in all age groups. Reasons for this variation are not clear, but might include the undergraduate and postgraduate training, differences in dental school curricula, availability of training courses in the area and patient choice.

A total of $84 \%$ of dentists undertaking sedation had undergone some kind of training, in 68\% of cases this included postgraduate 
training although the type of course cannot be deduced. This is higher than in previous studies, where $75 \%{ }^{9}$ and $5 \%{ }^{10}$ had received training. It should be noted that the question in the second report was framed to identify dentists who had sedation qualifications, and it is possible that respondents did not declare undergraduate or postgraduate training that did not result in a qualification. However, the General Dental Council guidance is clear, stating that dentists providing conscious sedation 'must have completed relevant postgraduate training. ${ }^{2}$ At least 29\% of practitioners in the Welsh survey have not met this standard, and 9\% have received no training at all. The undergraduate curriculum should provide a good introduction to the subject but also underline the need for postgraduate study, ${ }^{13}$ but studies predating this guidance demonstrated wide variation in sedation teaching within UK dental schools. ${ }^{14}$ Within Wales, over two thirds of dentists who offer sedation within their practice qualified between 1973 and 1992, a period when sedation teaching was not well covered in the undergraduate curriculum. Only 14 (16\%) of dentists offering sedation qualified after 1993. It is difficult to forecast what, if any, impact changes to the undergraduate curriculum will have on future graduates.

Those dentists who reported postgraduate training were also more likely to use a sedation certified dental nurse and have either another dentist or anaesthetist present while administering sedation.

The estimated travelling times reported to sedation centres in this study are good, with over half of journeys estimated to be less than 30 minutes. This presupposes that the dentist's estimate is accurate and that the patient's home is near the practice. Within certain areas of Wales we know that patients travel large distances to see a primary care dentist, so in many cases the dentists' estimates of time will be inaccurate.

In addition, where sedation is being used instead of a general anaesthetic in the past there is another dimension to consider. A general anaesthetic required one visit to complete all treatment, often with restorable teeth being extracted in a single visit. This equates to 60 minutes travelling for patients $(30$ minutes each way). Sedation involves more than one visit where multiple quadrant extractions or restorations are involved. It is not unusual for patients to need four or more appointments.

In 2001, a working group was set up by the National Centre for Continuing Postgraduate Education in Dentistry (NCCPED) who proposed a Standard Course on Conscious Sedation (England and Wales) $2001 .{ }^{15}$ From the information received by NCCPED in 2001, it was estimated that approximately 15\% of the dental services should be able to provide conscious sedation for a population group. This would depend on many factors such as geography, population density and the facilities in GDS, CDS and the hospital dental service (HDS). Investment in training was important to take these proposals forward.

In Wales, should the projections suggested by the NCCPED data be followed, as a rough estimate there would need to be 150 dentists in general dental practice (15\% of 996) and 17 in CDS (15\% of 115) trained to offer conscious sedation techniques. The response rate to the current questionnaire was almost 70\% and the 87 practitioners offering a conscious sedation service remains well short of this target. This questionnaire did not collect data from the HDS so it is not possible to estimate their contribution to sedation services in Wales.

\section{CONCLUSIONS}

Conscious sedation is offered by only $12 \%$ of primary care practitioners in Wales, although 53\% of practitioners had referred patients for sedation. There is evidence that a number of practitioners are not following GDC guidelines. With the reduction in the provision of general anaesthesia, there is a need to train more practitioners and dental nurses to undertake sedation in primary care.

1. A conscious decision; Report of an expert group chaired by the Chief Medical and Dental Officer. London: Department of Health, 2000.

2. Maintaining standards. Guidance to dentists on professional and personal conduct. London: General Dental Council, 2000.

3. General anaesthesia, sedation and resuscitation in dentistry: Report of an expert working party. London: Department of Health, 1990.

4. Kelly M et al. Adult Dental Health Survey. Oral Health in the United Kingdom in 1998. London: The Stationary Office, 2000.

5. Crawford A N. The use of nitrous oxide-oxygen inhalation sedation with local anaesthesia as an alternative to general anaesthesia for dental extractions in children. BrDent J 1990; 168: 395-398.

6. Kaufman $\mathrm{E}_{1}$ Jastak J T. Sedation for outpatient procedures. Compend Cont Educ Dent 1995: 16: 462-480.

7. Blain K M, Hill F J. The use of inhalational sedation and local anaesthesia as an alternative to general anaesthesia for dental extractions in children. Br Dent J 1998; 184: 608-611.

8. Wilson KE, Girdler N M, Welbury R R. Randomized, controlled, cross-over clinical trial comparing intravenous midazolam sedation with nitrous oxide sedation in children undergoing dental extractions. Br J Anaesth 2003: 91:850-856.

9. Whiston $S$, Prendergast $M J$, Williams $S A$. Sedation in primary dental care: an investigation in two districts of Northern England. Br Dent J 1998; 184: 390-393.

10. Foley J. The way forward for dental sedation and primary care? Br Dent J 2002; 193: $161-164$.

11. Welsh Assembly Government Statistical Bulletin, SB 7/2004, 29 January 2004.

12. Conscious sedation in the provision of dental care: Report of an expert group on sedation for dentistry. Standing Dental Advisory Committee, Department of Health 2003.

13. The first five years: A framework for undergraduate dental education. London: General Dental Council, 2002.

14. Leitch JA, Girdler NM. A survey of the teaching of conscious sedation in dental schools of the United Kingdom and Ireland. Brit Dent J 2000; 188: 211-216.

15. National Centre for Continuing Postgraduate Education in Dentistry. Standard Course on Conscious Sedation (England and Wales). London: Faculty Dental Surgery, Royal College of Surgeons of England, 2001. 